Research Paper

\title{
Increased breast cancer risk with HABP1/p32/gC1qR genetic polymorphism rs2285747 and its upregulation in northern Chinese women
}

\author{
Yongdong Jiang ${ }^{1, *}$, Hao Wu ${ }^{4, *}$, Jing Liu², Yanbo Chen ${ }^{1}$, Jingjing Xie ${ }^{1}$, Yashuang Zhao ${ }^{3}$, \\ Da Pang ${ }^{1}$ \\ ${ }^{1}$ Department of Breast Surgery, Harbin Medical University Cancer Hospital, Harbin, China \\ ${ }^{2}$ Department of Anesthesiology, The Second Affiliated Hospital, Harbin Medical University, Harbin, China \\ ${ }^{3}$ Department of Epidemiology, Public Health College of Harbin Medical University, Harbin, China \\ ${ }^{4}$ Sino-Russian Medical Research Center, Heilongjiang Academy of Medical Sciences, Harbin, China \\ *These authors contributed equally to this work \\ Correspondence to: Da Pang, email: pangdasir@163.com \\ Yashuang Zhao, email: zhao_yashuang@263.net
}

Keywords: breast cancer, HABP1 gene, single nucleotide polymorphisms, protein expression, Chinese

Received: January 04, $2016 \quad$ Accepted: January 06, $2017 \quad$ Published: January 19, 2017

\section{ABSTRACT}

Object: Hyaluronic acid binding protein 1 (HABP1/p32/gC1qR) is overexpressed in breast cancer. However, it is unknown whether HABP1 gene polymorphisms affect breast cancer risk. This study aims to evaluate the potential association of single nucleotide polymorphisms (SNPs) of HABP1 with breast cancer in northern Chinese women.

Results: The minor allele of rs2285747 was strongly associated with breast cancer with OR of $1.553(95 \% \mathrm{CI}=1.251-1.927)$. SNP rs 2285747 was also associated with high HABP1 protein expression under the co-dominant and dominant model ( $p=0.005, p=0.019$, respectively). For rs2472614, the patients with CG and GG were more likely to have HER2 negative tumors compared to CC $(p=0.015)$. For rs3786054, the patients with AG and GG were more likely to have HER2 and P53 negative breast cancer compared to AA ( $p=0.024, p=0.064$, receptively).

Materials and Methods: Seven SNPs were analyzed in 505 breast cancer patients and 505 controls using SNaPshot method. The associations between SNPs and breast cancer were examined by logistic regression. The associations of SNPs with HABP1 protein expression and disease characteristics were examined by chi-square test.

Conclusions: SNP rs2285747 of HABP1 increased breast cancer risk and elevated its protein expression in northern Chinese women.

\section{INTRODUCTION}

Breast cancer is presently the most frequently occurring cancer in Chinese women as in most western countries [1]. Although its exact etiology remains elusive, accumulating evidences suggest that breast cancer result from a complex interaction of genetic, environmental and lifestyle factors $[2,3]$. Many genes, such as highpenetrance susceptibility genes like BRCA1 [4] or BRCA2 [5] and low-penetrancce susceptibility genes[6], have been identified to be involved in breast tumorigenesis and progression. It is necessary to explore the potential mechanisms of these genes as effective molecular biomarkers in breast cancer.

Hyaluronic acid binding protein 1 (HABP1/p32/ $\mathrm{gClqR})$ is an cell adhesion protein and receptor for hyaluronic acid (HA) [7, 8]. HABP1 belongs to the hyaladherin family and may play an important role in regulating cellular signaling. The HABP1 gene locates at human chromosome 17p12-13, including six exons and five introns, and is highly expressed in various tissues and cell types [9]. HABP1 is a multi-functional protein involved in the activation of the complement and kinin systems [10]. Accumulating data demonstrates 
that upregulation of HABP1 promotes tumorigenesis by enhancing the proliferation, invasion and metastasis of cancer cells [11-13]. Overexpression of HABP1 is observed in several cancers, such as lung, gastric, colon adenocarcinomas, epidermal carcinoma, ovarian cancer, and endometrial cancer $[14,15]$. We previously found that the mRNA and protein levels of HABP1 significantly increased in breast cancer tissues, and upregulation of HABP1 was significantly associated with poor prognosis of breast cancer, including triple-negative breast cancer $[12,16]$. These studies suggest that HABP1 may be a novel biomarker for the prognosis of breast cancer. However, the underlying molecular mechanism of the dysregulation of HABP1 in breast cancer is largely unknown. It is well known that the genetic polymorphisms could affect gene expression. Thus, we may hypothesize that the genetic variants of HABP1 may associate with mRNA and protein expression and affect breast cancer risk and prognosis.

In this study, we selected seven potential functional SNPs (rs1050390, rs1050461, rs2285747, rs2472614, rs3786054, rs4790264, and rs8072363) in the HABP1 gene from the dbSNP and HapMap databases using a combined analysis of functional significance and Tag SNP strategies, and performed genotyping analyses in 505 breast cancer patients and 505 healthy controls to investigate the associations of HABP1 gene polymorphisms with breast cancer susceptibility, the survival, the clinicopathological features and the HABP1 protein expression in a population from northeast China, Heilongjiang Province.

\section{RESULTS}

\section{Subject characteristics}

The characteristics of 505 breast cancer cases and 505 cancer-free controls were summarized in Table 1. There were significant differences between cases and controls in the BMI, age at menarche, and breastfeeding duration. Compared with controls, cases tended to have significantly higher BMI, older age at menarche and longer breastfeeding duration. Of all subjects, 96 (19.0\%) cases and $70(13.1 \%)$ controls reported a family history of cancer in first-degree relatives, which was significantly different between cases and controls $(p<0.05)$. Among 96 patients who had family history of cancer, 13 had family history of breast cancer. No one had family history of breast cancer among 70 controls.

\section{Associations between SNPs and breast cancer risk}

The genotype distributions of HABP1 rs1050390, rs1050461, rs2285747, rs2472614, rs3786054, rs4790264 and rs8072363 and their associations of SNP with breast cancer risk were summarized in Table 2. The observed genotype frequencies of seven SNPs followed
Hardy-Weinberg equilibrium among the controls $(p>0.05$ for all seven SNPs). In the logistic regression models, compared with CC genotype of rs2285747, CG and GG genotypes were associated with an increased risk of breast cancer (adjusted OR $=1.619,95 \% \mathrm{CI}=1.232-2.129$ for $\mathrm{CG}$; $\mathrm{OR}=2.151,95 \% \mathrm{CI}=1.198-3.863$ for $\mathrm{GG}$, respectively) (Table 2). This SNP was also associated with an increased risk of breast cancer under a dominant model ( $\mathrm{GG}+\mathrm{CG}$ vs. $\mathrm{CC}, \mathrm{OR}=1.683,95 \% \mathrm{CI}=1.295-2.186)$. However, no significant association with breast cancer risk was observed for other six SNPs in the HABP1 gene.

\section{Association of SNPs with HABP1 protein expression}

We analyzed the correlations between HABP1 gene polymorphisms and protein expression (Table 3 ). HABP1 protein expression was shown in 390 breast cancer tissues. In the 10 cases of ductal carcinoma, 6 cases were low expression, and 4 cases were high expression. In the 359 cases of invasive ductal carcinoma, 133 cases were low expression, and 226 cases were high expression. In the other types, 10 cases were low expression, and 11 cases were high expression. The HABP1 protein expression in breast cancer tissue was shown in Figure 1, and the staining were localized within the cytoplasm. Under the co-dominant model, we found that the SNP rs228547 was significantly associated with higher/elevated HABP1 protein expression $(p=0.005)$. Moreover, the patients with genotypes CG and GG were associated with high HABP1 protein expression under the dominant model $(p=0.019)$. There were no significant associations between the other six SNPs and HABP1 protein expression under either codominant or dominant model $(p>0.05)$.

\section{Associations between SNPs and the clinicopathological features of breast cancer}

We next analyzed the effects of the seven SNPs in HABP1 gene on a series of clinicopathological features in the patient cohort, including clinic stage, tumor size, Bloom-Richardson grade, lymph node metastasis and the expressions of ER, PR, HER2 (also named as c-erbB-2), Ki67 and P53. The clinicopathologic features of breast cancer patients were shown in Table 4.

For rs2472614, it was found that the patients with genotype CG and GG were more likely to have HER2 negative tumors compared to the patients with genotype CC $(p=0.015)$. And for SNP rs3786054, the patients with genotype AG and GG were more likely to have HER2 and P53 negative breast cancer relative to the patients with genotype AA ( $p=0.024$ and $p=0.064$, receptively). In this research, for SNP rs1050390, rs1050461, rs2285747, rs4790264 and rs8072363, we did not find the significant association between these SNPs and the clinicopathological features $(p>0.05)$ (Supplementary Tables 1-7). 
Table 1: Distribution of selected variables in breast cancer cases and cancer-free controls

\begin{tabular}{cccc}
\hline Variables & Cases, $\boldsymbol{n}=\mathbf{5 0 5}$ & Controls, $\boldsymbol{n}=\mathbf{5 0 5}$ & $\boldsymbol{p}$ value \\
\hline Age (year) & $49.40 \pm 10.34(49.00)$ & $49.43 \pm 9.92(49.00)$ & 0.970 \\
Body mass index (kg/m) $)^{2}$, BMI & $24.29 \pm 3.41(24.09)$ & $23.11 \pm 2.84(23.05)$ & $<0.001$ \\
Age at menarche (year) & $15.42 \pm 1.79(15.00)$ & $15.06 \pm 1.85(15.00)$ & 0.002 \\
Age at first live birth (year) & $23.96 \pm 6.09(25.00)$ & $24.44 \pm 6.99(26.00)$ & 0.230 \\
Age at menopause (year) & $49.37 \pm 3.88(50.00)$ & $49.98 \pm 4.08(50.00)$ & 0.107 \\
Menopausal status & & & 0.526 \\
Pre-menopausal & $289(56.8)$ & $279(55.2)$ & $<0.001$ \\
Post-menopausal & $216(57.2)$ & $226(44.8)$ & 0.027 \\
Breastfeeding duration (months) & $16.03 \pm 13.13(12.00)$ & $11.53 \pm 7.51(12.00)$ & \\
Family history of cancer & & $70(13.1)$ & \\
Positive & $96(19.0)$ & $435(86.9)$ & \\
Negative & $409(81.0)$ & &
\end{tabular}

Note: Data presented as the mean \pm standard deviation (median) or number ( $\%$ of total number).

\section{HABP1 expression is correlated with breast cancer patient survival}

We then analyzed the associations of overall survival (OS) with seven SNPs in HABP1 gene, HABP1 protein expression, and clinicopathological features. Among 505 breast cancer patients, 41 was loss of follow up, and 323 remained alive after the expiration of the follow-up period. The OS rate was $69.6 \%$. We found that the clinic stage $\left(p=7.201 \times 10^{-7}\right)$, Bloom-Richardson grade (1 vs 3 : $p=0.030 ; 2$ vs $3: p=0.010)$, the status of $\mathrm{LN}$ involvement $(p=0.001), \mathrm{ER}\left(p=4.579 \times 10^{-4}\right), \mathrm{PR}(p=0.001), \mathrm{HER} 2$ $(p=0.020), \mathrm{P} 53(p=0.024), \mathrm{HABP} 1$ protein expression $(p=0.004)$, and $\operatorname{rs} 1050390(p=0.039)$, rs4790264 $(p=0.039)$, rs8072363 $(p=0.033)$ were associated with the OS under univariate analysis (Table 5). Under multivariate analysis (Table 5), the clinic stage ( $p=0.023$ ), the expression of ER $\left(p=1.019 \times 10^{-4}\right)$ and HABP1 protein
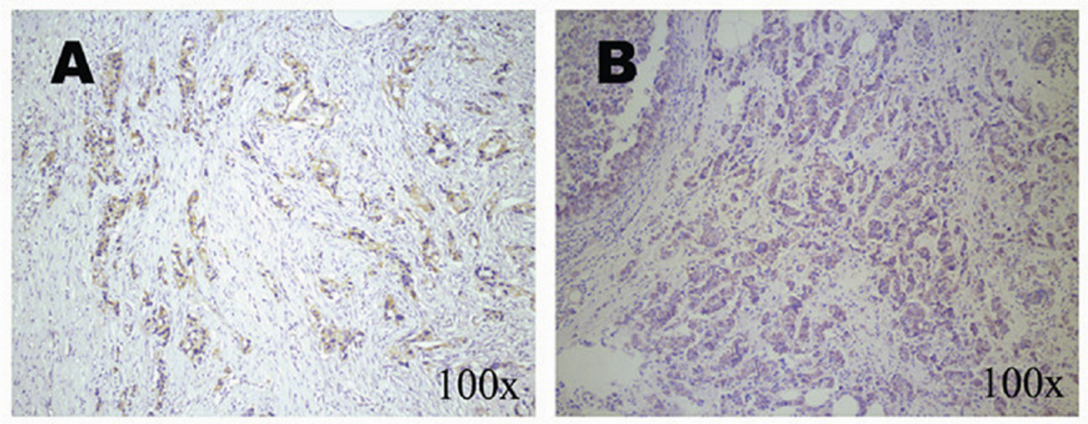

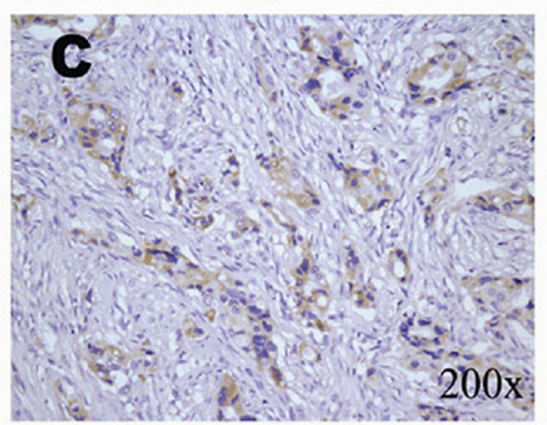

Low Expression

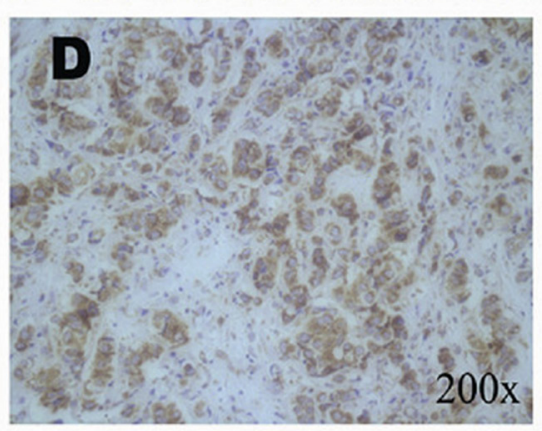

High Expression

Figure 1: Immunohistochemical staining of HABP1 in breast tissues. HABP1 immunoreactivity was observed mainly in the cytoplasm. Staining for each specimen is shown at two magnification: top, 100×; bottom, 200×. HABP1 protein low expression specimens $(\mathbf{A}, \mathbf{C})$; HABP1 protein low expression specimens $(\mathbf{B}, \mathbf{D})$. 
Table 2: The associations between HABP1 gene polymorphisms and breast cancer risk

\begin{tabular}{|c|c|c|c|c|c|}
\hline SNP & Genotype & Cases $n=505(\%)$ & Controls $n=505(\%)$ & OR $(95 \% \text { CI })^{a}$ & $p$ value \\
\hline \multirow[t]{5}{*}{ rs 1050390} & $\mathrm{AA}$ & $300(59.4)$ & $304(60.2)$ & 1 & \\
\hline & $\mathrm{AG}$ & $186(36.8)$ & $182(36.0)$ & $1.088(0.833-1.422)$ & 0.536 \\
\hline & GG & $19(3.8)$ & $19(3.8)$ & $1.085(0.554-2.125)$ & 0.812 \\
\hline & $\mathrm{AG}+\mathrm{GG}$ & $205(40.6)$ & $201(39.8)$ & $1.088(0.839-1.411)$ & 0.525 \\
\hline & $\mathrm{G}^{\mathrm{b}}$ & 22.2 & 21.8 & $1.066(0.858-1.324)$ & 0.563 \\
\hline \multirow[t]{5}{*}{ rs 1050461} & $\mathrm{CC}$ & $301(59.6)$ & $304(60.2)$ & 1 & \\
\hline & $\mathrm{CT}$ & $185(36.6)$ & $182(36.0)$ & $1.075(0.823-1.405)$ & 0.596 \\
\hline & $\mathrm{TT}$ & $19(3.8)$ & $19(3.8)$ & $1.080(0.551-2.114)$ & 0.823 \\
\hline & $\mathrm{CT}+\mathrm{TT}$ & $204(40.4)$ & $201(39.8)$ & $1.076(0.829-1.395)$ & 0.583 \\
\hline & $\mathrm{T}^{\mathrm{b}}$ & 22.1 & 21.8 & $1.314(1.058-0.851)$ & 0.613 \\
\hline \multirow[t]{5}{*}{ rs 2285747} & $\mathrm{CC}$ & $273(54.1)$ & $332(65.7)$ & 1 & \\
\hline & $\mathrm{CG}$ & $196(38.8)$ & $153(30.3)$ & $1.619(1.232-2.129)$ & 0.001 \\
\hline & GG & $36(7.1)$ & $20(4.0)$ & $2.151(1.198-3.863)$ & 0.010 \\
\hline & $\mathrm{CG}+\mathrm{GG}$ & $232(45.9)$ & $173(34.3)$ & $1.683(1.295-2.186)$ & $<0.001$ \\
\hline & $\mathrm{Gb}$ & 26.5 & 19.1 & $1.553(1.251-1.927)$ & $<0.001$ \\
\hline \multirow[t]{5}{*}{ rs2472614 } & $\mathrm{CC}$ & $203(40.2)$ & $205(40.6)$ & 1 & \\
\hline & $\mathrm{CG}$ & $234(46.3)$ & $230(45.5)$ & $1.082(0.822-1.424)$ & 0.575 \\
\hline & GG & $68(13.5)$ & $70(13.9)$ & $0.939(0.630-1.398)$ & 0.756 \\
\hline & $\mathrm{CG}+\mathrm{GG}$ & $302(59.8)$ & $300(59.4)$ & $1.047(0.808-1.357)$ & 0.729 \\
\hline & $\mathrm{G}^{\mathrm{b}}$ & 36.6 & 36.6 & $0.997(0.828-1.201)$ & 0.977 \\
\hline \multirow[t]{5}{*}{ rs3786054 } & AA & $195(38.6)$ & $196(38.8)$ & 1 & \\
\hline & $\mathrm{AG}$ & $235(46.5)$ & $236(46.7)$ & $1.048(0.794-1.382)$ & 0.742 \\
\hline & GG & $75(14.9)$ & $73(14.5)$ & $0.995(0.674-1.469)$ & 0.980 \\
\hline & $\mathrm{AG}+\mathrm{GG}$ & $310(61.4)$ & $309(61.2)$ & $1.035(0.797-1.344)$ & 0.798 \\
\hline & $\mathrm{G}^{\mathrm{b}}$ & 38.1 & 37.8 & $1.009(0.839-1.214)$ & 0.923 \\
\hline \multirow[t]{5}{*}{ rs4790264 } & $\mathrm{TT}$ & $300(59.4)$ & $304(60.2)$ & 1 & \\
\hline & TG & $186(36.8)$ & $182(36.0)$ & $1.088(0.833-1.422)$ & 0.536 \\
\hline & GG & $19(3.8)$ & $19(3.8)$ & $1.085(0.554-2.125)$ & 0.812 \\
\hline & $\mathrm{TG}+\mathrm{GG}$ & $205(40.6)$ & $201(39.8)$ & $1.088(0.839-1.411)$ & 0.525 \\
\hline & $\mathrm{G}^{\mathrm{b}}$ & 22.2 & 21.8 & $1.066(0.858-1.324)$ & 0.563 \\
\hline \multirow[t]{5}{*}{ rs8072363 } & $\mathrm{TT}$ & $300(59.4)$ & $304(60.2)$ & 1 & \\
\hline & $\mathrm{TC}$ & $186(36.8)$ & $183(36.2)$ & $1.088(0.833-1.422)$ & 0.536 \\
\hline & $\mathrm{CC}$ & $19(3.8)$ & $18(3.6)$ & $1.158(0.586-2.290)$ & 0.673 \\
\hline & $\mathrm{TC}+\mathrm{CC}$ & $205(40.6)$ & 201(39.8) & $1.094(0.844-1.419)$ & 0.497 \\
\hline & $\mathrm{C}^{\mathrm{b}}$ & 22.2 & 21.7 & $1.078(0.867-1.339)$ & 0.500 \\
\hline
\end{tabular}

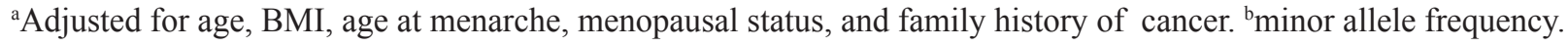

$(p=0.005)$ were associated with the OS. Kaplan-Meier analysis shown that HABP1 expression was significantly related to OS (log-rank test, $p=0.003$; Figure 2).

\section{DISCUSSION}

In this study, we found that SNP rs2285747 in the HABP1 gene could increase breast cancer risk and elevate HABP1 protein expression in our population. Kaplan-Meier analysis revealed that HABP1 expression was significantly associated with poor prognosis in breast cancer patients, univariate and multivariate analyses indicated that HABP1 expression was an independent prognostic factor. It suggested that HABP1 gene polymorphisms might increase breast cancer risk by affecting its protein expression and result in patient's 
Table 3: Association of HABP1 genetic polymorphisms with HABP1 protein expression

\begin{tabular}{|c|c|c|c|c|c|}
\hline \multirow{2}{*}{ SNP } & \multirow{2}{*}{ Genotype } & \multirow{2}{*}{ NO. } & \multicolumn{2}{|c|}{ HABP1 protein expression } & \multirow{2}{*}{$p$ value } \\
\hline & & & Low (\%) & High (\%) & \\
\hline \multirow[t]{4}{*}{ rs 1050390} & AA & 216 & $90(60.4 \%)$ & $126(52.3 \%)$ & \\
\hline & $\mathrm{AG}$ & 159 & $55(36.9 \%)$ & $104(43.2 \%)$ & \\
\hline & GG & 15 & $4(2.7 \%)$ & $11(4.6 \%)$ & 0.244 \\
\hline & $\mathrm{AG}+\mathrm{GG}$ vs $\mathrm{AA}$ & 174 & $59(39.6 \%)$ & $115(47.8 \%)$ & 0.117 \\
\hline \multirow[t]{4}{*}{ rs 1050461} & $\mathrm{CC}$ & 217 & $90(60.4 \%)$ & $127(52.7 \%)$ & \\
\hline & CT & 158 & $55(36.9 \%)$ & $103(42.7 \%)$ & \\
\hline & TT & 15 & $4(2.7 \%)$ & $11(4.6 \%)$ & 0.273 \\
\hline & $\mathrm{CT}+\mathrm{TT}$ vs $\mathrm{CC}$ & 173 & $59(39.6 \%)$ & $114(47.3 \%)$ & 0.137 \\
\hline \multirow[t]{4}{*}{ rs2285747 } & $\mathrm{CC}$ & 195 & $88(59.1 \%)$ & $107(44.4 \%)$ & \\
\hline & $\mathrm{CG}$ & 163 & $51(34.2 \%)$ & $112(46.5 \%)$ & \\
\hline & GG & 32 & $10(6.7 \%)$ & $22(9.1 \%)$ & 0.019 \\
\hline & $\mathrm{CG}+\mathrm{GG}$ vs $\mathrm{CC}$ & 195 & $61(40.9 \%)$ & $134(55.6 \%)$ & 0.005 \\
\hline \multirow[t]{4}{*}{ rs2472614 } & $\mathrm{CC}$ & 151 & $65(43.6 \%)$ & $86(35.7 \%)$ & \\
\hline & $\mathrm{CG}$ & 185 & $69(46.3 \%)$ & $116(48.1 \%)$ & \\
\hline & GG & 54 & $15(10.1 \%)$ & $39(16.2 \%)$ & 0.132 \\
\hline & $\mathrm{CG}+\mathrm{GG}$ vs $\mathrm{CC}$ & 239 & $84(56.4 \%)$ & $155(64.3 \%)$ & 0.118 \\
\hline \multirow[t]{4}{*}{ rs3786054 } & AA & 145 & $64(43.0 \%)$ & $81(33.6 \%)$ & \\
\hline & $\mathrm{AG}$ & 184 & $66(44.3 \%)$ & $118(49.0 \%)$ & \\
\hline & GG & 61 & $19(12.8 \%)$ & $42(17.4 \%)$ & 0.144 \\
\hline & $\mathrm{AG}+\mathrm{GG}$ vs $\mathrm{AA}$ & 245 & $85(57.1 \%)$ & $160(66.4 \%)$ & 0.064 \\
\hline \multirow[t]{4}{*}{ rs4790264 } & $\mathrm{TT}$ & 216 & $90(60.4 \%)$ & $126(52.3 \%)$ & \\
\hline & TG & 159 & $55(36.9 \%)$ & $104(43.2 \%)$ & \\
\hline & GG & 15 & $4(2.7 \%)$ & $11(4.6 \%)$ & 0.244 \\
\hline & $\mathrm{TG}+\mathrm{GG}$ vs TT & 174 & $59(39.6 \%)$ & $115(47.8 \%)$ & 0.117 \\
\hline \multirow[t]{4}{*}{ rs8072363 } & TT & 217 & $90(60.4 \%)$ & $127(52.7 \%)$ & \\
\hline & $\mathrm{CT}$ & 158 & $55(36.9 \%)$ & $103(42.7 \%)$ & \\
\hline & $\mathrm{CC}$ & 15 & $4(2.7 \%)$ & $11(4.6 \%)$ & 0.273 \\
\hline & $\mathrm{CT}+\mathrm{CC}$ vs TT & 173 & $59(39.6 \%)$ & $114(47.3 \%)$ & 0.137 \\
\hline
\end{tabular}

unfavourable prognosis. To the best of our knowledge, it is the first study to evaluate the relations between HABP1 genetic polymorphisms and breast cancer risk in a large cohort of Chinese northern women patients.

Our previous study showed that high HABP1 mRNA expression in breast cancer indicated poor prognosis and the 5-year survival rate was much lower in the high expression group compared with the low ones [12]. And we also found that HABP1 protein expression was an independent prognostic factor for breast cancer survival [17], especially for triple-negative breast cancer [16]. In the present study, we found that among the seven potential functional SNPs of the HABP1 gene, SNP rs2285747 was significantly associated with breast cancer risk and HABP1 protein expression in Chinese women of Heilongjiang Province. The carriers with CG and GG genotypes of rs2285747 had a higher risk of breast cancer and HABP1 protein expression. These results suggested that genetic variants in the HABP1 gene might associate with mRNA and protein expression of HABP1 and increase breast cancer susceptibility. SNP rs2285747 locates at the intron of HABP1 gene. The global MAF in the PUBMED was 0.390 . In the disease associated with intron, most of the genetic mutations are concentrated in the intron and exon junction. These mutuations could cause exon deletion or intron not being cut. And the variation in the middle position of intron could cause disease due to activation of the recessive splice sites and the change of shear effect [18]. In our study, we found that SNP rs2285747 was not associated with OS in survival analysis. But we found that the clinic stage, the expression of ER and HABP1 protein were associated with OS under multivariate analysis. 
Table 4: Summary of the clinicopathologic features of breast cancer studied

\begin{tabular}{|c|c|c|}
\hline Variables & & NO.(Percentage) \\
\hline \multirow[t]{5}{*}{ Clinic stage } & 0 & $14(2.77)$ \\
\hline & I & $112(22.18)$ \\
\hline & II & $214(42.38)$ \\
\hline & III-IV & $115(22.77)$ \\
\hline & Unknown & $50(9.90)$ \\
\hline \multirow[t]{3}{*}{ Tumor size $(\mathrm{cm})$} & $\leq 2$ & $178(35.25)$ \\
\hline & $>2$ & $267(52.87)$ \\
\hline & Unknown & $60(11.88)$ \\
\hline \multirow[t]{4}{*}{ Bloom-Richardson grade } & 1 & $35(6.93)$ \\
\hline & 2 & $276(54.65)$ \\
\hline & 3 & $125(24.75)$ \\
\hline & Unknown & $69(13.66)$ \\
\hline \multirow[t]{3}{*}{ Tumor type } & DCIS & $16(3.16)$ \\
\hline & IDC & $454(89.90)$ \\
\hline & Others & $35(6.93)$ \\
\hline \multirow[t]{3}{*}{ LN involvement } & Negative & $275(54.46)$ \\
\hline & Positive & $214(42.38)$ \\
\hline & Unknown & $16(3.17)$ \\
\hline \multirow[t]{3}{*}{ ER } & Negative & $190(37.62)$ \\
\hline & Positive & $312(61.78)$ \\
\hline & Unknown & $3(0.59)$ \\
\hline \multirow[t]{3}{*}{ PR } & Negative & $227(44.95)$ \\
\hline & Positive & $275(54.46)$ \\
\hline & Unknown & $3(0.59)$ \\
\hline \multirow[t]{3}{*}{ HER2 } & Negative & $361(71.49)$ \\
\hline & Positive & $29(5.74)$ \\
\hline & Unknown & $115(22.77)$ \\
\hline \multirow[t]{3}{*}{ Ki67 } & $\leq 14 \%$ & $191(37.82)$ \\
\hline & $>14 \%$ & $311(61.58)$ \\
\hline & Unknown & $3(0.59)$ \\
\hline \multirow[t]{3}{*}{ P53 } & Negative & $389(77.03)$ \\
\hline & Positive & $113(22.38)$ \\
\hline & Unknown & $3(0.59)$ \\
\hline \multirow[t]{3}{*}{ HABP1 protein expression } & Low & $149(29.51)$ \\
\hline & High & $241(47.72)$ \\
\hline & Unknown & $115(22.77)$ \\
\hline
\end{tabular}

Note: DCIS: ductal carcinoma in situ; IDC: infitrating ductal carcinoma.

SNP rs2472614, rs3786054, rs4790264, and rs8072363, located at the introns of HABP1 gene, were not associated with breast cancer risk in our study. Their global MAF in the PUBMED was $0.263,0.314,0.389$ and 0.390 , respectively. We found that SNP rs 1050390 and rs 1050461 , located at the 3' UTR of HABP1 gene, were not correlated with breast cancer risk in our population. Their global MAF in the PUBMED was 0.381 and 0.396, respectively.

Our studies also indicated that SNP rs2472614 and rs3786054 were significantly associated with HER2 negative breast cancer. Since HER2 is overexpressed at 
Table 5: Univariate and multivariate analysis for overall survival in breast cancer patients

\begin{tabular}{|c|c|c|c|c|}
\hline \multirow{2}{*}{ Variables } & \multicolumn{2}{|c|}{ Univariate analysis } & \multicolumn{2}{|c|}{ Multivariate analysis } \\
\hline & OR $(95 \%$ CI) & $p$ value & OR $(95 \% \mathrm{CI})$ & $p$ value \\
\hline Clinic stage $(0, \mathrm{I}, \mathrm{II} / \mathrm{III}-\mathrm{IV})$ & $2.369(1.684-3.332)$ & $7.201 \times 10^{-7}$ & $1.714(1.076-2.729)$ & 0.023 \\
\hline Tumor size $(\leq 2 />2)$ & $1.391(0.971-1.993)$ & 0.072 & & \\
\hline Bloom-Richardson grade $(1 / 2)$ & $3.040(1.112-8.311)$ & 0.03 & & \\
\hline Bloom-Richardson grade (1/3) & $3.870(1.390-10.773)$ & 0.01 & & \\
\hline LN involvement (Negative/Positive) & $1.790(1.276-2.510)$ & 0.001 & & \\
\hline ER (Negative/Positive) & $0.553(0.397-0.770)$ & $4.579 \times 10^{-4}$ & $0.402(0.254-0.637)$ & $1.019 \times 10^{-4}$ \\
\hline PR (Negative/Positive) & $0.572(0.409-0.798)$ & 0.001 & & \\
\hline HER2 (Negative/Positive) & $2.052(1.119-3.765)$ & 0.02 & & \\
\hline Ki67 ( $\leq 14 \% />14 \%)$ & $1.218(0.856-1.734)$ & 0.273 & & \\
\hline P53 (Negative/Positive) & $1.522(1.057-2.190)$ & 0.024 & & \\
\hline HABP1protein expression (Low/High) & $1.756(1.201-2.568)$ & 0.004 & $2.235(1.282-3.896)$ & 0.005 \\
\hline rs $1050390(\mathrm{AA} / \mathrm{AG})$ & $1.425(1.016-1.999)$ & 0.04 & & \\
\hline rs $1050390(\mathrm{AA} / \mathrm{GG})$ & $1.336(0.581-3.073)$ & 0.495 & & \\
\hline rs1050390 (AA/AG + GG) & $0.706(0.507-0.982)$ & 0.039 & & \\
\hline rs1050461 $(\mathrm{CC} / \mathrm{CT})$ & $1.383(0.985-1.941)$ & 0.061 & & \\
\hline rs1050461 (CC /TT) & $1.318(0.574-3.030)$ & 0.515 & & \\
\hline rs1050461 $(\mathrm{CC} / \mathrm{CT}+\mathrm{TT})$ & $1.377(0.989-1.916)$ & 0.058 & & \\
\hline rs2285747 (CC/CG) & $1.360(0.963-1.920)$ & 0.081 & & \\
\hline rs2285747 (CC/GG) & $1.372(0.741-2.538)$ & 0.314 & & \\
\hline rs2285747 (CC/CG + GG) & $1.362(0.978-1.896)$ & 0.067 & & \\
\hline rs2472614 (CC/CG) & $1.202(0.837-1.727)$ & 0.318 & & \\
\hline rs2472614 (CC/GG) & $1.182(0.704-1.986)$ & 0.527 & & \\
\hline rs2472614 (CC/CG + GG) & $1.198(0.848-1.692)$ & 0.305 & & \\
\hline rs3786054 (AA/AG) & $1.333(0.922-1.926)$ & 0.126 & & \\
\hline rs3786054 (AA/GG) & $1.150(0.686-1.927)$ & 0.596 & & \\
\hline rs3786054 (AA/AG + GG) & $1.287(0.905-1.831)$ & 0.16 & & \\
\hline rs4790264 (TT/TG) & $1.425(1.016-1.999)$ & 0.04 & & \\
\hline rs4790264 (TT/GG) & $1.336(0.581-3.073)$ & 0.495 & & \\
\hline rs4790264 (TT/TG + GG) & $1.416(1.018-1.971)$ & 0.039 & & \\
\hline rs8072363 (TT/TC) & $1.441(1.027-2.021)$ & 0.035 & & \\
\hline rs8072363 (TT/CC) & $1.342(0.584-3.085)$ & 0.488 & & \\
\hline rs8072363 (TT/TC + CC) & $1.431(1.029-1.992)$ & 0.033 & & \\
\hline
\end{tabular}

Note: (A/B), $\mathrm{A}$ is the reference.

the cell surface of tumor cells, and it might predict an unfavourable prognosis. But we did not find that the two SNPs were associated with OS in the survival analysis. So, the genotype of SNP rs2472614 and rs3786054 need further to be validated in a larger population.

The mechanism of the promotion of tumorigenesis by HABP1 is currently largely unknown. It was reported that HABP1 was a receptor for the tumor homing peptide Lyp1 which specifically recognized an epitope in tumor lymphatics and tumor cells in certain cancers
[13]. Knocking down HABP1 inhibited the growth of tumor cells [19]. In contrast, overexpression of HABP1 disturbed normal cell polarization and ultimately led to the malignant transformation of normal cells [20]. However, DNA sequencing of the gene encoding tumor-associated HABP1 did not reveal any consistent tumor specific mutations [21].

In conclusion, it is the first study to evaluate the association between HABP1 gene polymorphisms and breast cancer risk in women from Northeast China. Our 
results could provide a new idea that the mechanisms of HABP1 interfered with breast cancer, and suggest that HABP1 gene may be a potential biomarker for the early detection and prognosis, and a target for the development of molecular targeted therapy for breast cancer.

\section{MATERIALS AND METHODS}

\section{Subjects}

A cohort of 1,013 individuals, comprising 505 breast cancer patients and 508 healthy controls, were included in this study. Sporadic breast cancer patients were recruited from the Department of Breast Surgery, the Third Affiliated Hospital of Harbin Medical University. Breast cancer was diagnosed according to the patient's surgical and pathological analyses, and all the patients did not have radiotherapy or chemotherapy history before surgical operations. The control group was chosen from Han origin women living in Harbin, a province in the northeast of China. The control group was matched for age and ethnicity with patients, without a history of cancer. The participants were genetically not related in three generations. After providing informed consent, each participant was interviewed to collect detailed information on demographic characteristics (Table 1) and provided $5 \mathrm{ml}$ venous blood from September 2008 to May 2009. The clinicopathologic features of breast cancer patients were shown in Table 4. The patients received a minimum of four courses of anthracycline-based and/or taxanebased chemotherapy after surgery. Hormone treatment with tamoxifen or aromatase inhibitors was given to the patients with hormone receptor positive (ER or PR, or both). Her-2-positive patients who agreed to receive anti-Her-2 targeted therapy were treated with adjuvant trastuzumab for 1 year. This study was approved by the ethics committee of Harbin Medical University.

\section{SNPs selection and genotyping}

We performed a combined analysis of functional significance and Tag SNP strategies to select seven potential functional SNPs of the HABP1 gene from the dbSNP and HapMap databases. We selected tag SNPs from the entire length of the HABP1 gene (GRCh38. p7, chr17: 5,432,777-5,448,830) and additional $5 \mathrm{~kb}$ of upstream and $2 \mathrm{~kb}$ of downstream sequences to include the promoter and potential regulatory regions. The seven SNPs were rs1050390, rs1050461, rs2285747, rs2472614, rs3786054, rs4790264, and rs8072363, respectively. The minor allele frequency (MAF) of these SNPs was greater than $5 \%$, or pair-wise $r^{2}$ was more than 0.8 . Genomic DNA was isolated from EDTA anti-coagulated whole blood using the AxyPrep Blood Genomic DNA Miniprep Kit (Axygen Biotechnology, Union City, CA, USA). The SNaPshot SNP assay was carried out to detect the dimorphism at the seven SNP loci. The resulting data were analyzed with GeneMapperTM 4.0 Software (Applied Biosystems, Foster City, CA, USA). The reaction conditions and protocol for the genotyping were shown in Supplementary Materials and primer/ probe sequences were shown in Supplementary Table 8. To ensure qualitycontrol, genotyping was done without knowledge of case/ control status of the subjects, and a 5\% random sample

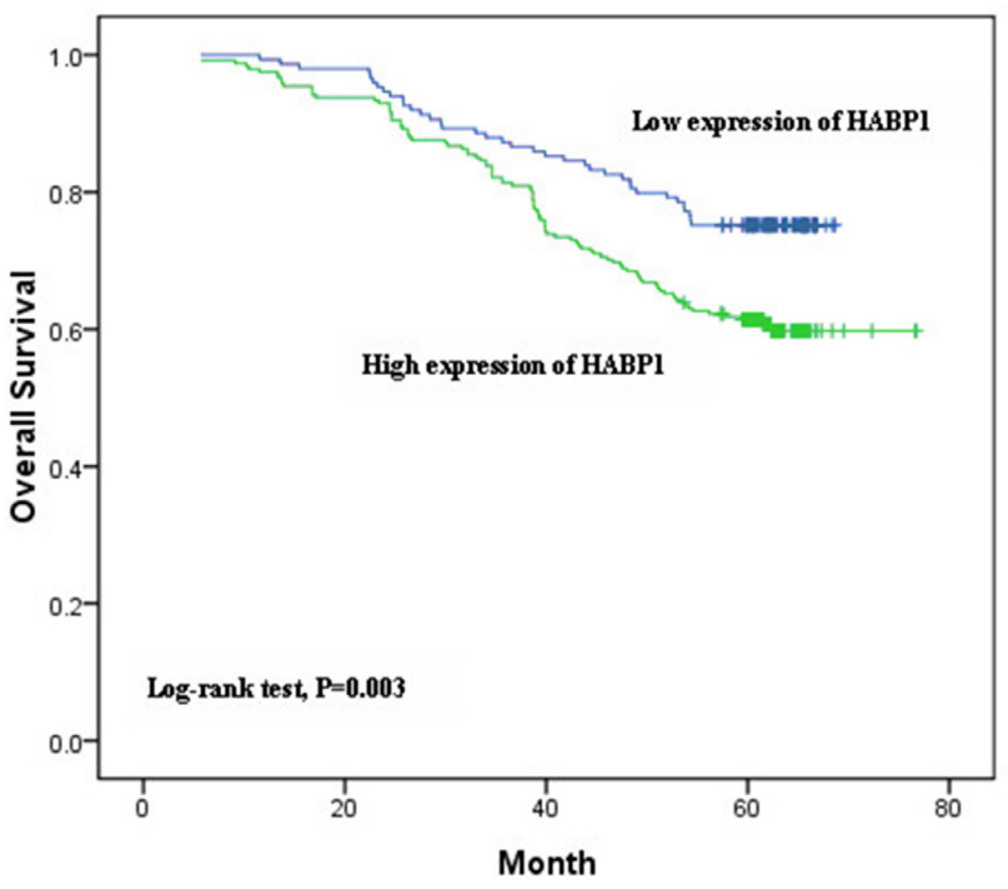

Figure 2: Kaplan-Meier survival analyses of breast cancer patients. 
of cases and controls was genotyped twice by different persons; the reproducibility was $100 \%$. Genotyping failed in three controls due to DNA quality and the average call rate for all SNPs was higher than 99\%. All data from these 3 women were excluded from analyses. Therefore, 505 breast cancer cases and 505 controls were included in the final analyses.

\section{Immunohistochemistry}

The formalin-fixed, paraffin-embedded samples were cut into $4 \mu \mathrm{m}$ and stained with $\mathrm{H} \& \mathrm{E}$ for tumor confirmation. The tissue sections were dried at $70^{\circ} \mathrm{C}$ for $3 \mathrm{~h}$. After deparaffinization and hydration according to the standard procedures, sections were washed in phosphatebuffered saline (PBS; $3 \times 3 \mathrm{~min}$ ). The washed sections were treated with $3 \% \mathrm{H}_{2} \mathrm{O}_{2}$ for $15 \mathrm{~min}$ in the dark. After washing in distilled water, sections were washed in PBS $(3 \times 5 \mathrm{~min})$ and were then treated with $0.01 \mathrm{~mol} / \mathrm{L}$ citrate buffer ( $\mathrm{pH}$ 6.0) and were exposed to heat induced epitope retrieval for $2 \mathrm{~min}$. The sections were incubated overnight at $4^{\circ} \mathrm{C}$ with primary antibody HABP1 (1:200 dilution, a recombinant rabbit monoclonal antibody, Abcam: ab131284). After washing in PBS $(3 \times 5 \mathrm{~min})$, each section was incubated with the secondary antibody (an anti-rabbit antibody, ZSGB-BIO: PV6001, K156605C) at room temperature for $30 \mathrm{~min}$. After washing in PBS $(3 \times 5 \mathrm{~min})$, each section was treated with diaminobenzadine (DAB: ZSGB-BIO: ZLI-9018, K152317J) working solution at room temperature for $3 \mathrm{~min}$, and then washed in distilled water.

The immunohistochemical staining of HABP1 were scored by combining the proportion and intensity of positively stained tumor cells. The staining intensity was classified as 0 (no staining), 1 (weak staining), 2 (moderate staining), and 3 (strong staining). The percentage of positive cells was classified as 0 (no positive tumor cells), 1 ( $\leq 10 \%$ positive tumor cells), 2 (10-50\% positive tumor cells), and 3 ( $\geq 50 \%$ positive tumor cells). Staining index (SI) was calculated as a proportion score $\times$ staining intensity score. The final scores $\leq 4$ were considered to be low expression, and the remainder were classified as high expression. Cases with discrepancies were re-reviewed simultaneously by the original two pathologists (NXM and SHT) and a senior pathologist (LXM) until a consensus was reached.

\section{Follow-up}

Patients were followed regularly for 5 years at the Third Affiliated Hospital of the Harbin Medical University. The follow-up period was 6 months during the first 2 year, and the follow-up period was 12 months during the next 3 year. 464 participants were followed up and 41 patients were excluded. The participation rate is $91.88 \%$. Patients were followed up from the end of the treatment every year by the ways of the annual outpatient follow-up system, telephone and letters. Clinical records were obtained from the follow-up department of the hospital. Survival was calculated in months from the date of diagnosis to whichever of the following occurred first: the date of death, the date last known to be alive, or the follow-up cutoff date (June 1, 2014) in our study. The causes of death of breast cancer patients were breast cancer or others.

\section{Statistical analysis}

The genotype frequencies were tested for HardyWeinberg equilibrium using the chi-square test among the controls. Differences between cases and controls in demographic characteristics were evaluated by the chisquare test (for categorical variables) or Student's $t$-test (for continuous variables). Associations between genotypes and breast cancer risk were estimated by computing odds ratios (ORs) and 95\% confidence intervals (CIs) from logistic regression with adjustment for age, BMI, age at menarche, menopausal state, and family history of cancer. Homozygotes for non-risk alleles were the reference group. Heterozygotes and homozygous risk allele genotypes were compared with the reference group, respectively. The dominant model was analyzed with homozygote for risk allele and heterozygote versus the reference group. The Kaplan-Meier survival curves and log rank tests were used for survival curves. The Cox proportional hazards model was used to estimate the independent prognostic factors for OS. The Pearson's chi-square test was used to evaluate the correlations between SNPs of HABP1 gene and the HABP1 protein expression. All statistical tests were two-sided, and a $p$ value equal to or less than 0.05 was considered statistically significant and a $p$ value less than 0.1 was considered a possible trend that could be explored further in larger study groups. Statistical analyses were performed using SPSS for Windows software (version 16.0; SPSS, Chicago, IL, USA).

\section{ACKNOWLEDGMENTS}

The authors thank all patients and healthy volunteers for providing blood samples and all the research staff for their contributions to this project.

\section{CONFLICTS OF INTEREST}

The authors declare that they have no conflicts of interest.

\section{GRANT SUPPORT}

This study was supported by Heilongjiang Postdoctoral Fund, China (Yongdong Jiang, Grant no. LBH-Z13158), the China Postdoctoral Science Fund, (Yongdong Jiang, Grant no. 2015M571445), the National 
Key Technology Support Program (Grant Number 2013BAI09B00, 2014BAI09B00), and the Project of Heilongjiang Province Applied Technology Research and Development (Grant Number GA13C201).

\section{REFERENCES}

1. Fan L, Strasser-Weippl K, Li JJ, St Louis J, Finkelstein DM, Yu KD, Chen WQ, Shao ZM, Goss PE. Breast cancer in China. Lancet Oncol. 2014; 15:e279-289.

2. Kelsey JL, Gammon MD. The epidemiology of breast cancer. CA Cancer J Clin. 1991; 41:146-165.

3. McPherson K, Steel CM, Dixon JM. ABC of breast diseases. Breast cancer-epidemiology, risk factors, and genetics. BMJ. 2000; 321:624-628.

4. Miki Y, Swensen J, Shattuck-Eidens D, Futreal PA, Harshman K, Tavtigian S, Liu Q, Cochran C, Bennett LM, Ding W, et al. A strong candidate for the breast and ovarian cancer susceptibility gene BRCA1. Science. 1994; 266:66-71.

5. Wooster R, Bignell G, Lancaster J, Swift S, Seal S, Mangion J, Collins N, Gregory S, Gumbs C, Micklem G. Identification of the breast cancer susceptibility gene BRCA2. Nature. 1995; 378:789-792.

6. Easton DF, Pooley KA, Dunning AM, Pharoah PD, Thompson D, Ballinger DG, Struewing JP, Morrison J, Field H, Luben R, Wareham N, Ahmed S, Healey CS, et al. Genome-wide association study identifies novel breast cancer susceptibility loci. Nature. 2007; 447:1087-1093.

7. Deb TB, Datta K. Molecular cloning of human fibroblast hyaluronic acid-binding protein confirms its identity with P-32, a protein co-purified with splicing factor SF2. Hyaluronic acid-binding protein as $\mathrm{P}-32$ protein, co-purified with splicing factor SF2. J Biol Chem. 1996; 271:2206-2212.

8. Gupta S, Datta K. Possible role of hyaluronectin on cell adhesion in rat histiocytoma. Exp Cell Res. 1991; 195:386-394.

9. Tye AJ, Ghebrehiwet B, Guo N, Sastry KN, Chow BK, Peerschke EI, Lim BL. The human $\mathrm{gC} 1 \mathrm{qR} / \mathrm{p} 32$ gene, C1qBP. Genomic organization and promoter analysis. J Biol Chem. 2001; 276:17069-17075.

10. Hu G, Chong RA, Yang Q, Wei Y, Blanco MA, Li F, Reiss M, Au JL, Haffty BG, Kang Y. MTDH activation by 8 q22 genomic gain promotes chemoresistance and metastasis of poor-prognosis breast cancer. Cancer cell. $2009 ; 15: 9-20$

11. Zhang X, Zhang F, Guo L, Wang Y, Zhang P, Wang R, Zhang N, Chen R. Interactome analysis reveals that C1QBP (complement component 1, q subcomponent binding protein) is associated with cancer cell chemotaxis and metastasis. Mol Cell Proteomics. 2013; 12:3199-3209.

12. Chen YB, Jiang CT, Zhang GQ, Wang JS, Pang D. Increased expression of hyaluronic acid binding protein 1 is correlated with poor prognosis in patients with breast cancer. J Surg Oncol. 2009; 100:382-386.

13. Fogal V, Zhang L, Krajewski S, Ruoslahti E. Mitochondrial/ cell-surface protein $\mathrm{p} 32 / \mathrm{gC} 1 \mathrm{qR}$ as a molecular target in tumor cells and tumor stroma. Cancer Res. 2008; 68:7210-7218.

14. Yu G, Wang J. Significance of hyaluronan binding protein (HABP1/P32/gC1qR) expression in advanced serous ovarian cancer patients. Exp Mol Pathol. 2013; 94:210-215.

15. Zhao J, Liu T, Yu G, Wang J. Overexpression of HABP1 correlated with clinicopathological characteristics and unfavorable prognosis in endometrial cancer. Tumour Biol. 2014.

16. Wang J, Song Y, Liu T, Shi Q, Zhong Z, Wei W, Huang S, Pang D. Elevated expression of HABP1 is a novel prognostic indicator in triple-negative breast cancers. Tumour Biol. 2015; 36:4793-4799.

17. Niu M, Sun S, Zhang G, Zhao Y, Pang D, Chen Y. Elevated expression of HABP1 is correlated with metastasis and poor survival in breast cancer patients. Am J Cancer Res. 2015; 5:1190-1198.

18. Copertino DW, Hallick RB. Group II and group III introns of twintrons: potential relationships with nuclear pre-mRNA introns. Trends Biochem Sci. 1993; 18:467-471.

19. Fogal V, Richardson AD, Karmali PP, Scheffler IE, Smith JW, Ruoslahti E. Mitochondrial p32 protein is a critical regulator of tumor metabolism via maintenance of oxidative phosphorylation. Mol Cell Biol. 2010; 30:1303-1318.

20. Bialucha CU, Ferber EC, Pichaud F, Peak-Chew SY, Fujita Y. p32 is a novel mammalian Lgl binding protein that enhances the activity of protein kinase Czeta and regulates cell polarity. J Cell Biol. 2007; 178:575-581.

21. Rubinstein DB, Stortchevoi A, Boosalis M, Ashfaq R, Ghebrehiwet B, Peerschke EI, Calvo F, Guillaume T. Receptor for the globular heads of C1q (gC1q-R, p33, hyaluronan-binding protein) is preferentially expressed by adenocarcinoma cells. Int J Cancer. 2004; 110:741-750. 